\title{
Clearing Break Points of Overcurrent Protection Coordination for Parallel Distribution Feeder
}

\author{
Mahmoud A. Elsadd, \\ Abdel-Maksoud I. Taalab \\ Electrical Engineering Department \\ Faculty of Engineering, Menoufia University \\ 32511 Shebin Elkom, Egypt
}

\author{
Tamer A. Kawady \\ Electrical Engineering Department \\ Faculty of Engineering and Islamic \\ Architecture \\ Umm Al-Qura University, Makkah, SA \\ Menoufia University, Egypt
}

\author{
Nagy I. Elkalashy \\ Electrical Engineering Department \\ Faculty of Engineering, Taif University \\ Taif, Saudi Arabia \\ Menoufia University, Egypt
}

\begin{abstract}
This paper presents a modified overcurrent protection system to overcome the break points of a parallel distribution feeder protection. For realizing an appropriate protection setting, two concepts are introduced, and their performance is evaluated. These concepts are the adaptive coordination exploiting smart grid information and the modified coordination methods. The modified coordination is adjusted with changing of the contemporary worst fault point. A comparative study is done between the adaptive, modified, and conventional coordination concepts. For investigation purposes, a $11 \mathrm{kV}$ distribution feeder is modelled using the Matlab/Simulink package. The results provide evidence of the efficacy of the proposed modified coordination concept for parallel distribution feeders.
\end{abstract}

Keywords - coordination; Distribution feeder; Overcurrent protection; Smart grid.

\section{INTRODUCTION}

Overcurrent relays are usually used for the protection of interconnected sub-transmission systems, distribution systems, or as a secondary protection of transmission systems [1]-[5]. Regarding the relay function, overcurrent relays are categorized as phase and earth overcurrent relays. Also concerning the time delay operation point of view, overcurrent relays are classified as definite time and inverse time types [6]. Inverse time relays are the most utilized type where a shorter delay in clearing dangerous faults close to power supplies is substantial. However, coordination using inverse time relays is more complex [6]. Each protection relay in the power system requires being coordinated with the relays protecting the adjacent equipment. The coordination of protective relays consists of selecting their suitable settings (pickup current and time dail setting) to verify the basic protective function with the requirements of dependability, security, and speed [7]-[8]. If backup protections are not well coordinated, break points can be happened. This problem appears more with multi-loop or parallel feeders. In parallel feeders, some events can change the topology of the grid as maintenance or emergency outage of one feeder. This usually changes the amplitudes of the short-circuit fault currents in various parts of the grid. Accordingly, break points of the protection coordination can happen for certain fault at certain network topology.

If the advantages of available modern technologies are used properly, they may promote the coordination of overcurrent relays. Coordination of overcurrent relays is an important concept for realization self-healing networks. The benefits of appropriate coordination of overcurrent relays are to detect and remove the selected minimum faulty parts as fast as possible, to reduce operating costs, and to save time.

In order to overcome the break points, several sets of protection settings are designed in accordance with different network topologies. In [9]-[10], the sets of protection settings have been proposed based on the distributed generation interconnection (in service and out of service). An adaptive overcurrent protection scheme with two setting groups - one for grid connected and the second for operation of islanded mode has been introduced in [11]-[12]. However, the concept of setting sets was not evaluated with break points on parallel feeders.

This paper introduces an adaptive and modified overcurrent protection approaches. They can overcome break points in conventional coordination with parallel feeders. A comparison between the adaptive and modified method versus the conventional one is presented. The modified concept is simpler than the adaptive one in applications of protection coordination.

\section{CONVENTIONAL RELAYS COORDINATION}

\section{A. Protection Coordination Principles}

Generally, the OC relays setting includes properly selecting pickup currents $\left(I_{P}\right)$ and time dial settings (TDSs). The relays are coordinated with correct and precise adjustment of the mentioned settings. $I_{P}$ of each OC relay must verify:

$$
I_{P i \min } \leq I_{P i} \leq I_{P i \max }
$$

\section{(1)}

From (1), the pickup current setting for any relay is determined by two limits, namely, the maximum load and the minimum fault currents [13]-[14]. However, choosing TDS is more computation burden [15]-[17]. This is necessary for maintaining the security of the protection system so that:

$$
t_{b}-t_{p} \geq C T I
$$

where $t_{b}$ and $t_{p}$ are the operating times of the backup and primary protective relays for any fault, respectively. $C T I$ is a 
coordination time interval between the relays that is usually specified between 0.2 to $0.5 \mathrm{~s}$ [18]. The operating time characteristic of the inverse relay is known as in [18]. The larger the current is, the shorter the operating time will be. Therefore, (2) is adjusted at the maximum jointed fault current measured by the two relays. This extracted fault current is called the worst condition to verify (2) with any other fault currents in the relay jurisdiction.

\section{B. Overcurrent Protection Coordination for Parallel Feeder}

Fig. 1 shows a single-end-fed distribution system with two parallel-feeders, six overcurrent relays, and two outgoing feeders. The outgoing feeders use overcurrent relay R1 as a primary protection. Relays R2 and R3 are installed on both terminals of the parallel feeders to protect them. Relay R4 is also used as the main protection of the busbar close to power substation. Relay R2 is a directional unit in to avoid the isolation of two parallel feeders in case of only one faulted feeder. Whereas all other relays R1, R3, and R4 are nondirectional units. With faults on the outgoing feeders, relays R1 and R3 are primary and backup protection, respectively. Both relays must operate in a correct coordination. On the other hand, relay R2 does not sense these faults, because it is a directional unit. With faults on one feeder of the two parallel feeders, relays R2 and R3 installed on this feeder are primary protection. On the other hand, relay R4 is a backup to relay R3 of the faulty feeder. Also, Relay R3 installed on the healthy feeder is a backup to the relay $\mathrm{R} 2$ of the faulty feeder.

The conventional procedure for calculating the time dial settings is considered as following. The downstream relay $\mathrm{R} 1$ and the direction relays $\mathrm{R} 2 \mathrm{a}$ and $\mathrm{R} 2 \mathrm{~b}$ are adjusted at their lowest time dial setting. The adjustment step of TDS can be reduced to 0.02. Under the worst fault level for the coordination between relays $\mathrm{R} 1$ and $\mathrm{R} 3$, the $T D S$ of relay $\mathrm{R} 3$ is determined. This fault level is considered as a solid threephase fault at the breaker terminal CB1 with one feeder in service only. Under a solid three-phase fault at the breaker terminal CB2 of relay R2, the coordination between relay R2 of a certain feeder and relay R3 of the other one is also carried out. Another value for TDS of relay R3 is determined. The maximum value from the two values of $T D S$ of relay $\mathrm{R} 3$ is selected to maintain the coordination constraint in (2). Also, the coordination between relays R3 and R4 is carried out using the fault at the breaker terminal CB3 of the relay R3 with one or two feeders in service. Finally, the value of $T D S$ of relay $\mathrm{R} 4$ is determined. This coordination procedure is applied on a practical test system to declare the break points.

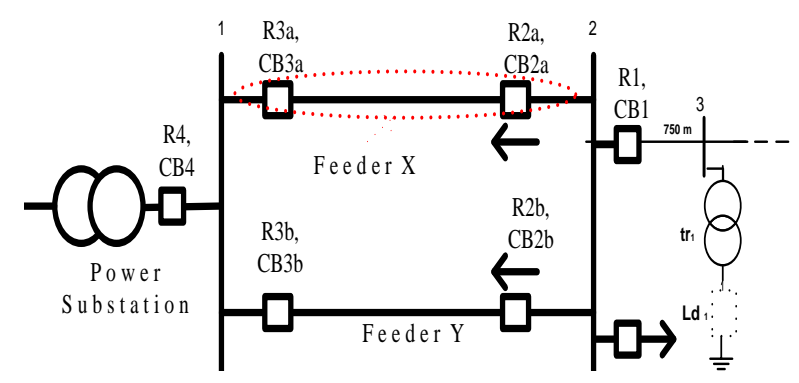

Fig. 1. Parallel feeder and overcurrent protection relays.

\section{SIMULATED SYSTEM}

The distribution feeder shown in Fig. 1 was selected as a simulation example for this study. The feeder consists of two overhead parallel feeder's sections, feeders $\mathrm{X}$ and $\mathrm{Y}$, cascaded with underground cable. The main transformer in the substation is a $25 \mathrm{MVA}, 66 / 11 \mathrm{kV}$. It is considered as a typical example of nine load busses as described in Fig. 1. MATLAB is used to simulate the selected distribution feeder. Each of overhead and underground feeder segments was modeled with $\pi$-circuits, where their parameters are illustrated in Table I. Each load was represented as a threephase balanced load implemented with a series combination of RLC branches. At the specified frequency, the load exhibits constant impedance. After applying the procedure mentioned in the previous subsection, the maximum loads, current transformer (CT) ratios, pickup currents, and time dial settings are summarized in Table II. The TDS values in this table are calculated based on the mentioned coordination rules in the previous subsection.

\section{BREAK POINTS IN CONVENTIONAL COORDINATION}

Conventional coordination was carried out at a certain topology with one feeder only in service of the two parallel feeders. Fault current at backup relay higher than at primary relay can break the coordination between overcurrent relays. This can happen with faults occurred on Busbar 2 as shown in Fig. 1 when the two parallel feeders are in service. At these faults, the backup relay $\mathrm{R} 4$ sees current more than the current seen by the primary relay R3. Accordingly, the backup relay will trip unnecessarily. However, with solidly fault the operating time of relay $\mathrm{R} 4$ is more than the operating time of relay $\mathrm{R} 3$, the difference between them is less than CTI as shaded cells highlighted by dashed circle shown in Table III. On the other hand, with faults associated with fault resistance, the operating time of backup relay R4 is less than the time of the primary relay $\mathrm{R} 3$ as seen by the shaded cells with solid circle shown in Table III. Therefore, the conventional coordination for parallel feeders is not the optimal coordination for these grid topologies.

\begin{tabular}{cccc}
\multicolumn{5}{c}{ TABLE I. The feeder parameter. } \\
\hline Symbol & Quantity & Overhead/cable & Unit \\
\hline \hline $\mathrm{R}_{1}$ & Positive sequence resistance & $0.2361 / 0.196$ & $(\Omega / \mathrm{km})$ \\
\hline $\mathrm{R}_{0}$ & Zero sequence resistance & $0.3826 / 0.245$ & $(\Omega / \mathrm{km})$ \\
\hline $\mathrm{L}_{1}$ & Positive sequence inductance & $1.3630 / 0.39$ & $(\mathrm{mH} / \mathrm{km})$ \\
\hline $\mathrm{L}_{0}$ & zero sequence inductance & $5.2156 / 1.170$ & $(\mathrm{mH} / \mathrm{km})$ \\
\hline $\mathrm{C}_{1}$ & Positive sequence capacitance & $0.0067 / 0.241$ & $(\mu \mathrm{F} / \mathrm{km})$ \\
\hline $\mathrm{C}_{0}$ & zero sequence capacitance & $0.0041 / 0.161$ & $(\mu \mathrm{F} / \mathrm{km})$ \\
\hline
\end{tabular}

TABLE II. Conventional protection coordination settings.

\begin{tabular}{ccccc}
\hline Relay & $\begin{array}{c}\text { Maximum } \\
\text { load } \\
\text { Current, A }\end{array}$ & $\begin{array}{c}\mathrm{CT} \\
\text { ratio }\end{array}$ & $\begin{array}{c}I_{P}, \\
\mathrm{~A}\end{array}$ & TDS \\
\hline \hline $\mathrm{R}_{1}$ & 247 & $250 / 5$ & 7.41 & 0.02 \\
\hline $\mathrm{R}_{0}$ & 241 & $250 / 5$ & 7.23 & 0.02 \\
\hline $\mathrm{L}_{1}$ & 241 & $250 / 5$ & 7.23 & 0.0755 \\
\hline $\mathrm{L}_{0}$ & 247 & $250 / 5$ & 7.41 & 0.1608 \\
\hline
\end{tabular}


TABLE III. Current seen by the relays, TDS, and operating time of the relays using the conventional coordination with two feeders in service.

\begin{tabular}{|c|c|c|c|c|}
\hline \multirow{2}{*}{\multicolumn{2}{|c|}{ Fault Point }} & \multicolumn{3}{|c|}{ Relays and their $T D S s$} \\
\hline & & R1 & R3 & $\mathrm{R} 4$ \\
\hline \multirow{2}{*}{ Just beyond R1 } & If (A) & 3580 & 1790 & 3580 \\
\hline & top (s) & 0.0603 & 0.3251 & 0.4851 \\
\hline \multirow[t]{2}{*}{ At Busbar 2} & If $(\mathrm{A})$ & $\overline{-}$ & 1790 & 3580 \\
\hline & $\mathrm{t}_{\mathrm{op}}(\mathrm{s})$ & $\overline{-}$ & -0.3251 & $0.4851=$ \\
\hline \multirow{2}{*}{$\begin{array}{l}\text { At Busbar } 2 \\
\text { with } \mathrm{Rf}=5 \Omega\end{array}$} & If $(\mathrm{A})$ & - & 765 & 1530 \\
\hline & $\mathrm{t}_{\mathrm{op}}(\mathrm{s})$ & $\overline{-}$ & 0.6998 & 0.7825 \\
\hline \multirow{2}{*}{$\begin{array}{l}\text { At Busbar } 2 \\
\text { with } \mathrm{Rf}=8 \Omega\end{array}$} & If $(\mathrm{A})$ & - & 558 & 1116 \\
\hline & $\mathrm{t}_{\mathrm{op}}(\mathrm{s})$ & $\overline{-}$ & 1.2122 & 1.0096 \\
\hline \multirow{2}{*}{ Just beyond R3 } & If $(\mathrm{A})$ & - & 6885 & 6885 \\
\hline & $\mathrm{t}_{\mathrm{op}}(\mathrm{s})$ & $\overline{-}$ & 0.1741 & 0.3741 \\
\hline
\end{tabular}

\section{PROPOSED COORDINATION}

Two coordination concepts are introduced. The first is an adaptive setting concept for relay R3 with communicating data. The second is a modified setting concept using the proposed point of the worst fault condition.

\section{A. Adaptive Concept}

Relay R3 has two sets of the time dial as in Fig. 2. One is used when two parallel feeders are connected. The second is used when one feeder of them is not connected to the network. Time dial setting of the relay R3 is changed based on signal from the status of circuit breakers associated with another feeder.

The calculation method of time dial setting of the relay R3 considering one feeder only in service (The first setting of relay $\mathrm{R} 3=0.0755$ ) is the same conventional coordination principles. The second setting of relay R3 is obtained by using the fault level which is a solid three-phase fault at the breaker terminal associated with relay R1 (CB1) when the two feeders are connected. Under this condition, the current seen by relay $\mathrm{R} 3$ is half the current seen by relay $\mathrm{R} 1$ as in Fig. 2. This leads to the second time dial setting of the relay R3 (The second setting of relay R3=0.0604) is lower than the first one.

Each of the adaptive relays $\mathrm{R} 3 \mathrm{a}, \mathrm{R} 3 \mathrm{~b}$ has a communicated channel between them and relevant two circuit breakers in another parallel feeder (CB2b and CB3b, $\mathrm{CB} 2 \mathrm{a}$ and $\mathrm{CB} 3 \mathrm{a})$. The setting of the relay located at upstream of feeder $\mathrm{X}$ is based on signal from status of two circuit breakers located at feeder $\mathrm{Y}$ as in Fig. 1. If the two circuit breakers located at one feeder of them become open, a message is sent through the communication media to the relay in the second feeder. Then, this relay changes its setting. This concept does not give a complete solution for clearing break points founded in conventional method as shown in shaded cells highlighted by dotted circle in Table IV. This occurred with faults associated with fault resistance at busbar 2 .
TABLE IV. Current seen by the relays, TDS, and operating time of the relays using the adaptive concept with two feeders in service.

\begin{tabular}{|c|c|c|c|c|c|}
\hline & \multirow{3}{*}{ Fault Point } & \multicolumn{4}{|c|}{ Relays and their $T D S s$} \\
\hline & & $\mathrm{R} 1$ & $\overline{\mathrm{R} 3}$ & $\overline{\mathrm{R} 4}$ & $\overline{\mathrm{R} 2}$ \\
\hline & & 0.02 & 0.0604 & 0.1608 & 0.02 \\
\hline \multirow[t]{2}{*}{ Just beyond R1 } & If (A) & 3580 & 1790 & 3580 & 1790 \\
\hline & top (s) & 0.0603 & 0.2603 & 0.4851 & - \\
\hline \multirow[t]{2}{*}{ At Busbar 2} & If $(\mathrm{A})$ & 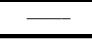 & 1790 & 3580 & 1790 \\
\hline & $\mathrm{t}_{\mathrm{op}}(\mathrm{s})$ & $\overline{-}$ & 0.2603 & 0.4851 & - \\
\hline \multirow{2}{*}{$\begin{array}{r}\text { At Busbar } 2 \text { with } \\
\mathrm{Rf}=8 \Omega\end{array}$} & If $(\mathrm{A})$ & - & 558 & 1116 & 558 \\
\hline & $\mathrm{t}_{\mathrm{op}}(\mathrm{s})$ & & 0.9698 & 1.0096 & $\ldots$ \\
\hline \multirow{2}{*}{$\begin{array}{r}\text { At Busbar } 2 \text { with } \\
\mathrm{Rf}=10 \Omega\end{array}$} & If $(\mathrm{A})$ & - & 478.5 & 957 & 478.5 \\
\hline & $\mathrm{t}_{\mathrm{op}}(\mathrm{s})$ & & 1.5037 & 1.1749 & 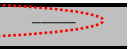 \\
\hline \multirow{3}{*}{ Just upstream $\mathrm{R}_{2 \mathrm{a}}$} & If $(\mathrm{A})$ & $\overline{ }$ & 1790 & 3580 & 1790 \\
\hline & $\mathrm{t}_{\mathrm{op}}(\mathrm{s})$ & & R3a: & & R2a: 0.086 \\
\hline & & & $\begin{array}{r}0.2603 \\
\text { R3b: }\end{array}$ & 0.4851 & \\
\hline
\end{tabular}

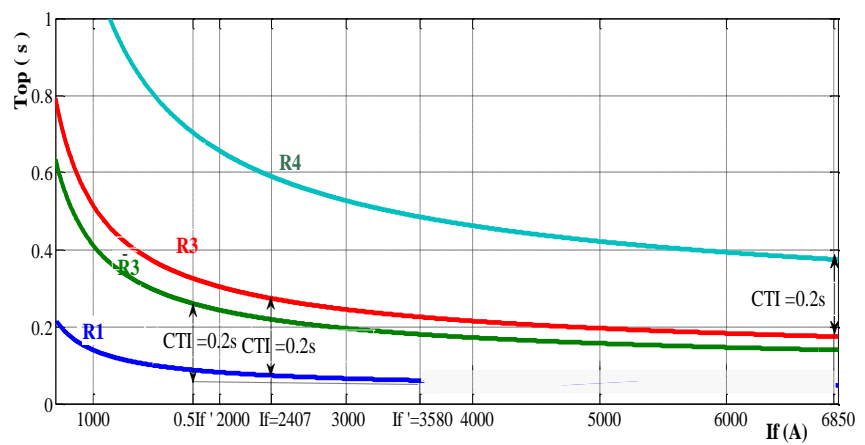

Fig. 2. Time-current characteristic of the overcurrent relays.

Also, another limitation of this method is with faults, upstream relay $\mathrm{R} 2 \mathrm{a}$ or $\mathrm{R} 2 \mathrm{~b}$, in any of the two parallel feeders. With these faults (feeder $\mathrm{X}$ as example), the current seen by primary relay $\mathrm{R} 2 \mathrm{a}$ is nearly equal to seen by the backup relay. The time dial setting of the backup relay $\mathrm{R} 3 \mathrm{~b}$ is the lowest one (setting of $\mathrm{R} 3=0.0604$ ). Then, the difference between operating time of backup and primary relays may not be enough where it is less than the coordination time interval seen by the final row in Table 4.

\section{B. Modified Concept}

In this concept, the break points in the conventional coordination are treated by changing the time dial setting of the relay $\mathrm{R} 4$. The coordination between relays $\mathrm{R} 3$ and $\mathrm{R} 4$ is carried out at a suggested fault level. The suggested fault is a three-phase fault at the busbar 2 when two feeders are in service with fault resistance $10 \Omega$. This concept makes $T D S$ for R4 is little more than the calculated with conventional coordination. The new coordination is summarized in Table IV. Busbar 2 represents the downstream point in the primary jurisdiction protected by relay R3. At this point, the current passing through primary protection relay $\mathrm{R} 3$ is half passing through backup protection relay $\mathrm{R} 4$. This may make the operation of relay R4 faster than relay R3. Therefore, the worst point is modified in this concept to be at busbar 2. To identify the remaining of the worst condition, a series of faults were carried out at busbar 2. The study proved that 
lowest fault current at busbar 2 is the worst condition when the two feeders are in service. On the other hand, taking low fault currents gives a higher time dial setting of the relay R4. Therefore, relay R4 is delayed with faults at busbar 1 . This makes fault at busbar 1 continues for long time and the power transformer may damage. To maintain the selectivity and speed of relays, the level of fault current associated with fault resistance equal to $10 \Omega$ is selected. The advantages of this method are removing the break points associated with the conventional coordination and maintaining the selectivity between relays until fault resistance equal to 10 $\Omega$. Furthermore, additional communication data or breaker status is not required.

\section{A systematic Comparison}

A comparative study was carried out to check the response of the modified, adaptive, and conventional overcurrent protection systems. For this study, five different fault conditions have been simulated with one and two feeders in service as shown in Table V. These faults were three phase fault type with fault resistance ranging from 0 until $15 \Omega$. All faults have been tested three times by the modified, adaptive, and conventional overcurrent protection systems. As revealed from the results, the adaptive overcurrent coordination did not guarantee the proper selectivity. For example, a three-phase fault at busbar 2 with fault resistance equal to $9 \Omega$ was profiled with operating time of backup relay R4 is less than primary relay R3 as in shaded cells in Table V. Accordingly, the proposed modified overcurrent protection is the most suitable for coordinating overcurrent relays with parallel feeders.

\section{CONCLUSIONS}

In this paper, two concepts for coordinating overcurrent relays in parallel distribution feeders have been proposed to clear the break points of conventional coordination methodology. The adaptive concept is more difficult to be implemented as it needs dedicated communication links between relays. The modified concept has maintained the selectivity of overcurrent relays properly than the adaptive one. On the other hand, modified concept has characterized by the ease of implementation. Using this concept, isolated sections under certain conditions have been reduced comparing to conventional coordination. Further development will consider the impact of the distributed generation on protection coordination in the distribution network.

\section{REFERENCES}

[1] Urdaneta, A. J. Perez, L. G. and Restrepo H. Optimal coordination of directional overcurrent relays considering dynamic changes in the network topology. IEEE Trans. Power Del., vol. 12, no. 4, pp. 14581464, Oct. 1997

[2] M. A. Elsadd, N. I. Elkalashy, T. A. Kawady, A.-M. I. Taalab, and Matti Lehtonen (2016) Incorporating Earth Fault Location in Management Control Scheme for Distribution Networks, In IET Gen Transm Distrib, 10(10):2389 - 2398.

[3] M. Elsadd, N. Elkalashy, T. Kawady, and A. Taalab, "Earth fault location determination independent of fault impedance for distribution networks," in International Transactions on Electrical Energy Systems, vol. 27, no 5, pp. 2389-2398, 5 May 2017.

[4] L. S. Khalifa, M. A. Elsadd, R. A. A. El-Aal, S. M. El-Makkawy, "Enhancing Recloser-Fuse Coordination using Distributed Agents in Deregulated Distribution Systems", 2018 Twentieth International
Middle East Power Systems Conference (MEPCON), Dec. 2018, pp. 948-955.

[5] O. Abood, M. Elsadd, and S. Guirguis, "Incorporating Deoxyribonucleic Acid in AES Scheme for Enhancing Security and Privacy Protection," Journal of Theoretical and Applied Information Technology, vol. 97. no. 02, pp. 349-360, January 2019.

[6] Mason, C. R. The Art and Science of Protective Relaying. John Wiley and Sons, New York, 1956.

[7] .R.C.Van Warrington, Protective Relays, Their Theory and Practice. John Wiley and Sons, New York, 1969.

[8] El-khattam W. and Sidhu T. S. Resolving the impact of distributed renewable generation on directional overcurrent relay coordination: A case study. IET Renew. Power Gen., vol. 3, pp. 415-425, 2009.

[9] Baran M. and El-Markabi I. Adaptive over current protection for distribution feeders with distributed generators. Proc. IEEE Power Eng. Soc. Power Syst. Conf. Expo., 2004, pp. 715-719.

[10] Mahat P., Zhe C., Bak-Jensen B., and Bak C. L. A simple adaptive overcurrent of distribution systems with distributed generation. IEEE Trans. Smart Grid, vol. 2, no. 3, pp. 428-437, Sep. 2011.

[11] Cheung H., Hamlyn A., Cungang Y., and Cheung R. Network-based adaptive protection strategy for feeders with distributed generations. in Proc. IEEE Canada Elect. Power Conf., 2007, pp. 514-519.

[12] Abyaneh H. A., Al-Dabbagh M., and Karegar H. K. A new optimal approach for coordination of overcurrent relays in interconnected power systems. IEEE Trans on Power Delivery 2003; 18(2): 430435.

[13] Zeienldin H., Ei-Saadamy E. F., and Salama M. A. Novel problem formulations for directional overcurrent relay coordination. Proceedings of Large Engineering systems Conference on Power Engineering, July 28-30, 2004, Canada: 48-52.

[14] Noghabi A. S., Sadeh J., and Mashhadi H. R. Considering different network topologies in optimal overcurrent relay coordination using a hybrid. IEEE Trans. Power Del., vol. 24, no. 4, pp. 1857-1863, Oct.2009.

[15] Noghabi A. S., Sadeh J., and Mashhadi H. R. Optimal coordination of directional overcurrent relays considering different network topologies using interval linear programming. IEEE Trans. Power Del., vol. 25, no. 3, pp. 1348-1854, Jul. 2010.

[16] Urdaneta A. J., Pérez L. G., Gómez J. F., Feijoo B., and González M. Presolve analysis and interior point solutions of the linear programming coordination problem of directional overcurrent relays. Elect. Power Energy Syst., vol. 23, pp. 819-825, 2000.

[17] Zeineldin H. H., El-Saadany E. F., and Salama M. A. Optimal coordination of overcurrent relays using a modified particle swarm optimization. Elect. Power Energy Syst., vol. 11, no. 76, pp. 988-995, 2006.

[18] Gers J. M. and Holmes E. J. Protection of Electricity Distribution Networks- 2nd Edition. The Institution of Electrical Engineers, London, United Kingdom 2004.

\section{Creative Commons Attribution License 4.0 (Attribution 4.0 International, CC BY 4.0)}

This article is published under the terms of the Creative Commons Attribution License 4.0 https://creativecommons.org/licenses/by/4.0/deed.en_US 
TABLE V. Comparison between the performance of conventional, adaptive, and modified overcurrent protections.

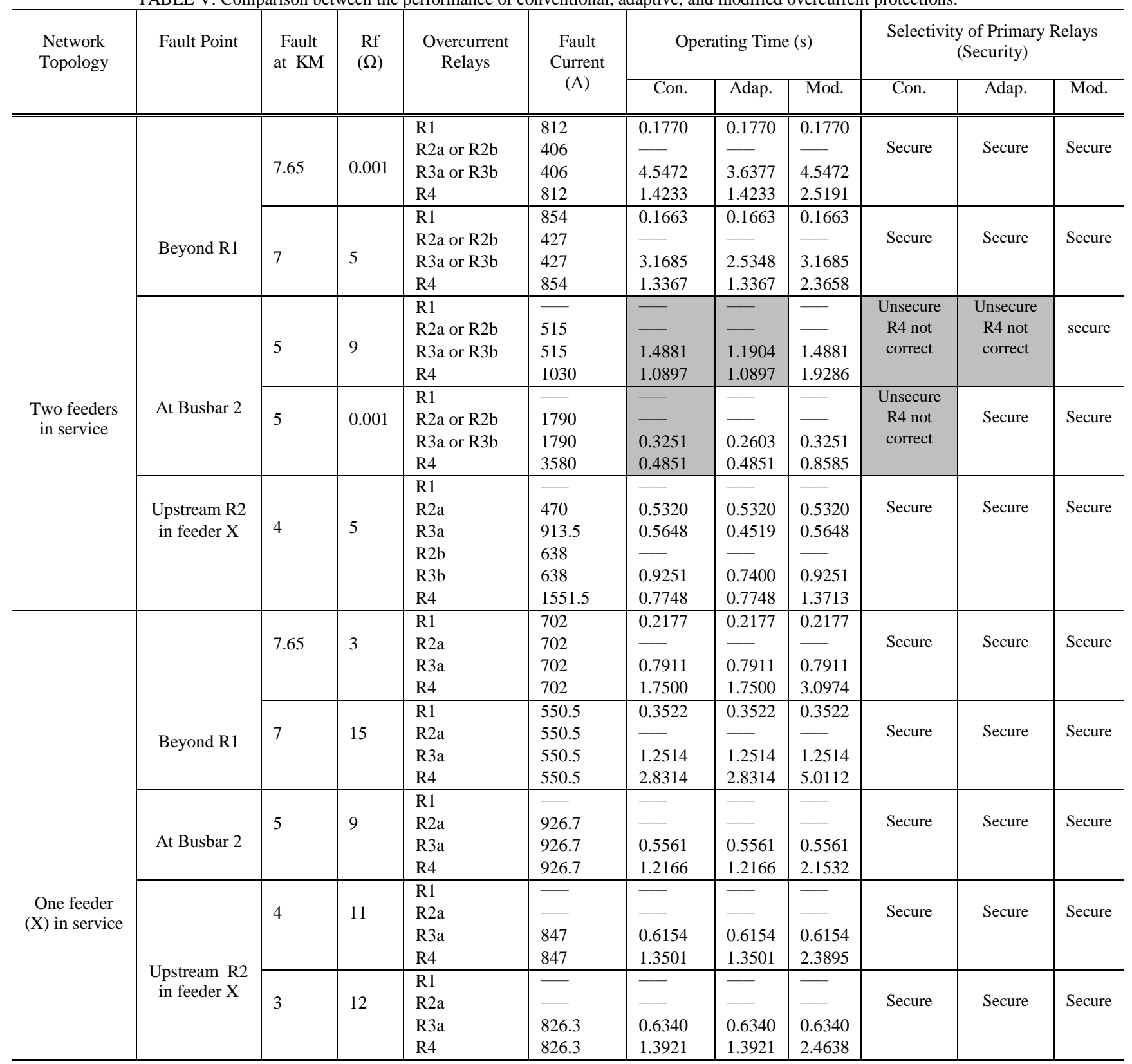

